\title{
Correction to: Drug dose and animal welfare: important considerations in the treatment of wildlife
}

\author{
Kate Mounsey ${ }^{1,2} \cdot$ Robert J. Harvey $^{1,2} \cdot$ Victoria Wilkinson $^{3} \cdot$ Kotaro Takano $^{1,2} \cdot$ Julie Old $^{4} \cdot$ Hayley Stannard ${ }^{5}$. \\ Leanne Wicker $^{6} \cdot$ David Phalen $^{7} \cdot$ Scott Carver ${ }^{3}$
}

Published online: 1 March 2022

(c) The Author(s), under exclusive licence to Springer-Verlag GmbH Germany, part of Springer Nature 2022

\section{Correction to: Parasitology Research https://doi.org/10.1007/s00436-022-07460-4}

The authors note that the "Abstract" section that appears in the original article is incorrect, and the actual abstract was omitted during production.

The original article has been corrected.

Publisher's Note Springer Nature remains neutral with regard to jurisdictional claims in published maps and institutional affiliations.

The original article can be found online at https://doi.org/10.1007/ s00436-022-07460-4.

Kate Mounsey

kmounsey@usc.edu.au

1 School of Health and Behavioural Sciences, University of the Sunshine Coast, Maroochydore, QLD 4558, Australia

2 Sunshine Coast Health Institute, Birtinya, QLD 4556, Australia

3 School of Natural Sciences, University of Tasmania, Hobart, TAS 7005, Australia

4 School of Science, Western Sydney University, Hawkesbury campus, Penrith, NSW 2751, Australia

5 School of Agricultural, Environmental and Veterinary Sciences, Charles Sturt University, Wagga Wagga, NSW 2678, Australia

6 Wildlife Conservation and Science, Zoos Victoria, Parkville, VIC 3052, Australia

7 Sydney School of Veterinary Science, Faculty of Science, The University of Sydney, Sydney, NSW 2006, Australia 